\title{
Bacillomycins - The Effective Molecules in Plant Disease Management
}

\author{
P. Suneeta*, K. Eraivan Arutkani Aiyanathan and S. Nakkeeran \\ Department of Plant Pathology, Centre for Plant Protection Studies, Tamil Nadu Agricultural \\ University (TNAU), Coimbatore-641003, Tamil Nadu, India \\ *Corresponding author
}

A B S T R A C T

\begin{abstract}
Keywords
Bacillomycins,

Molecules,

Plant disease

management

Article Info

Accepted:

10 January 2018

Available Online:

10 February 2018

Bacillomycins are the cyclic lipopeptides belonging to the iturin family produced by Bacillus spp. mostly Bacillus subtilis, which are biosynthesized by multimodular proteins termed as NRPSs (non-ribosomal peptide synthetases) genes. There is tremendous research on Bacillus spp. lipopeptides or antimicrobial peptides (AMPs) showing great antagonistic potentiality of these strains, especially with bacillomycins producing genes. This review highlights the bacillomycins structure, biosynthesis, mode of action and the noteworthy antagonistic Bacillus strains with bacillomycin producing genes which have the huge potential of commercialization of these antibiotics. Moreover, an outlook is also given in a view of commercializing potential of bacillomycins against plant diseases, though there are commercial applications of bacillomycins in bio-pharmaceutical, food, textiles, pulp/paper \& drug industries.
\end{abstract}

\section{Introduction}

The ubiquitous Bacillus spp. with great genetic and metabolic diversity leads to the production of several antibiotics and enzymes which has increasing demand in biotechnological approaches and plant protection. Several hundred wild-type $B$. subtilis strains have been collected, with the potential to produce more than two dozen antibiotics with an amazing variety of structures. All of the genes specifying antibiotic biosynthesis combined amount to $350 \mathrm{~kb}$; however, as no strain possesses them all, an average of about $4-5 \%$ of a $B$. subtilis genome is devoted to antibiotic production (Stein, 2005).
The potential of $B$. subtilis to produce antibiotics has been recognized for 50 years. Peptide antibiotics represent the predominant class. In the context of biocontrol of plant diseases, the three families of Bacillus lipopeptides - surfactins, iturins and fengycins were at first mostly studied for their antagonistic activity for a wide range of potential phytopathogens, including bacteria, fungi and oomycetes (Ongena and Jacques, 2007). Among them, Iturin is a large family of cyclic lipopeptides produced by Bacillus sp. It consists of iturin $\mathrm{A}$, iturin $\mathrm{C}$, iturin $\mathrm{D}$, iturin $\mathrm{E}$, bacillomycin $\mathrm{D}$, bacillomycin $\mathrm{F}$, bacillomycin L, bacillomycin Lc and mycosubtilin (Peypoux et al., 1973, 1978, 1979, 1984; Besson et al., 1976; Besson and Michel, 1986; 
Cho et al., 2000; Yu et al., 2002). This review highlights the importance of cyclic lipopeptide, Bacillomycins of Iturin family produced by various species of Bacillus (especially by Bacillus subtilis) in wider environment, its isolation, biosynthesis with a keen view on biosynthetic gene clusters studied in various strains of Bacillus, molecular method of detection, mode of action and gathered the works on antagonism of Bacillus spp. with bacillomycin producing genes against plant pathogens which also involves the attempt to commercializing production methods of the particular antibiotic, bacillomycin.

\section{Bacillomycins}

The first form of bacillomycin isolated from Bacillus subtilis strain was Bacillomycin D a new antibiotic of the iturin group was described by using mild acid hydrolysis and by cleavage of the molecule with Nbromosuccinimide (Peypoux et al., 1973, 1981). Then structure of bacillomycin L came into light which is a cyclic lipopeptide from iturin group characterized by a liposoluble $\beta$ amino acid linked to a peptide moiety containing $\mathrm{D}$ and $\mathrm{L}$ a-amino acids (Besson $e t$ al., 1977, 1978). The complete structural analysis of peptidolipid antibiotics, Bacillomycin D and Bacillomycin L isolated from Bacillus subtilis was done by Peypoux et al., (1984). Similarly, Bacillomycin F a new antibiotic of Iturin group was also first reported from Bacillus subtilis (Peypoux et al., 1985). Another modified form of antifungal antibiotic of the iturin class, Bacillomycin Lc was isolated from a strain of Bacillus subtilis as a set of 5-congeners by using chemical and spectrometric analyses (Eshita et al., 1995).

\section{Structure of bacillomycins}

The general structure of an iturin is composed of heptapeptide with a conserved chiral sequence LDDLLDL which is cyclized by amide bond formed between $\alpha-\mathrm{COO}$ group of 7th amino acid and $\beta-\mathrm{NH} 2$ group of $\beta$ - amino fatty acid (BAA), which in turn is peptide bonded through its $\alpha$-COO group to $\mathrm{N}$ terminal amino acid (Fig. 1). The members of iturin family exhibit heterogeneity at 1, 4, 5, 6 and 7 amino acid position/s in the peptide moiety as well as in the BAA length, which varies from 14 to 17 carbons. On the basis of variation of amino acids in peptide moiety, bacillomycins have been classified as: bacillomycin $\mathrm{D}$, bacillomycin $\mathrm{F}$, bacillomycin L and bacillomycin Lc (Fig.1) (Peypoux et al., 1978, 1984; Besson et al., 1976; Besson and Michel, 1986).

Bacillomycin $\mathrm{D}$ is a mixture of two homologous lipopeptides: the lipid moiety consists of 3-amino-12-methyltridecanoic acid or 3-amino-12-methyltetradecanoic acid; the peptide moiety contains one residue of each of the following seven amino acids: L-Asn-DTyr-D-Asn-L-Pro-L-Glu-D-Ser-L-Thr and shared the common amino acid sequence AsnTyr-Asn with the other iturin members (Peypoux et al., 1981). Bacillomycin D has a monomeric structure, its molecular weight of 1039 calculated for one lipid /I-amino acid and a heptapeptide moiety (Fig.2) was in good agreement with the experimental value, determined by the thermo-osmotic method, of 1060 32 (Peypoux et al., 1984).

Bacillomycin Lc differs from Bacillomycin $\mathrm{L}$ by sequence changes from aspartate- 1 to asparagine-1 and from glutamine-5 to glutamate-5. Also by the sequence positions of a side chain amide and a carboxylic acid which are at position 5 (L-Glutamine) and at position 1 (L-aspartic acid) respectively in case of bacillomycin L (Eshita et al., 1995). The structure of Bacillomycin $F$ was confirmed as a mixture of homologous peptidolipids, essentially $\mathrm{C}_{51} \mathrm{H}_{80} \mathrm{~N}_{12} \mathrm{O}_{14}$ and $\mathrm{C}_{52} \mathrm{~N}_{82} \mathrm{~N}_{12} \mathrm{O}_{14}$. The lipid moiety consists of 
minor isoCI5, anteisoC15 $\mathrm{B}$-amino acids and major isoC16, isoC17 and anteisoC17 $\beta$-amino acids (Peypoux et al., 1985).

\section{Biosynthesis of bacillomycins}

The non-ribosomal synthesis of peptide antibiotics is widespread among bacteria and fungi (Finking and Marahiel, 2004). Large multienzymes or multimodular proteins termed non-ribosomal peptide synthetases (NRPSs) that are composed of modularly arranged catalytic domains (Fig.3), catalyse all necessary steps in peptide biosynthesis including the selection and ordered condensation of amino acid residues (Stein, 2005; Chen et al., 2009).

Each elongation cycle in non-ribosomal peptide biosynthesis needs the cooperation of three core domains: (i) The adenylation domain (550 amino acid residues) selects its cognate amino acid and generates an enzymatically stabilized amino-acyl adenylate. This mechanism resembles the aminoacylation of tRNA synthetases during ribosomal peptide biosynthesis. (ii) The thiolation or peptidyl carrier domain $(80 \mathrm{aa})$ is equipped with a 4'-phosphopantetheine (PPan) prosthetic group to which the adenylated amino acid substrate is transferred and thioesterified under release of AMP.

Thus, the PPan cofactor acts as thiotemplate and as a swinging arm to transport intermediates between the various catalytic centres. The peptidyl carrier proteins are posttranslationally converted from inactive apoforms to their active holoforms by dedicated PPan transferases (Lambalot et al., 1996). (iii) The formation of a new peptide bond is catalysed by condensation domains (450 aa) located between each pair of adenylation and peptidyl carrier domains. The linear assembly line-like arrangement of multiple of such core units (i-iii) ensures the co-ordinated elongation of the peptide product (Stein, 2005; Chen et al., 2009).

In most of the cases the non-ribosomal peptide biosynthesis is terminated by macrocyclization of the peptide product, whereby parts of the molecule distant in the constructed linear peptide chain are covalently linked to one another (Kohli and Walsh, 2003).

Typically, such reactions are catalysed by thioesterase domains at the $\mathrm{C}$ terminal end of the NRPS assembly line. The depicted mechanism of peptide biosynthesis has been outlined in the concept of the 'Multiple Carrier Model of Non-ribosomal Peptide Biosynthesis at Modular Multienzymatic Templates' (Stein et al., 1996). Mechanistically, NRPSs utilize multiple Ppan carriers for covalent binding of monomers and growing chains following colinearity rule (Guenzi et al., 1998; Stein, 2005). The system is highly flexible in which naturally rearrangements can be easily achieved within a relatively short period, permitting the random evolution of compounds that provide selective advantages. Striking examples for such flexibility are the systems specifying the biosynthesis of the closely related compounds of the iturin family (Stein, 2005) (Fig.3).

\section{Biosynthetic gene cluster of bacillomycin}

The gene clusters devoted to non-ribosomal synthesis of cyclic lipopeptides, surfactin, fengycin and iturin-like antibiotics are widely spread in B. subtilis and related strains (Stein, 2005). The first evidence for bacillomycin D enzymatic synthesis through activation of amino acids was provided by Besson and Michel (1992) who purified an enzyme fraction which catalyzed the adenylation of amino acids present in the lipopeptide. Similarly, the mycosubtilin operon is the first operon encoding an iturin lipopeptide that was completely sequenced (Duitman et al., 1999). 
Then the modular organizations of other peptide synthetase gene clusters were sequenced like iturin A synthetase operon and compared the adenylation and condensation domains within the iturin group peptides (Tsuge et al., 2001; Moyne et al., 2004).

The operon encoding the bacillomycin D synthetases in B. subtilis AU195 was identified, cloned and characterized by Moyne et al., (2004). The Bacillomycin D operon spans $37.8 \mathrm{~kb}$ with 4 ORFs: bamD, bamA, bamB and bam $C$ which share the structural organization of the Mycosubtilin and Iturin A operon (Moyne et al., 2004). In B. amyloliquefaciens FZB42, the bmy gene cluster is an insertion within its genome and separated by only $25 \mathrm{~kb}$ from the fengycin gene cluster. It comprised of four genes (bmyD, bmyA, bmyB and bmyC) without counterparts in B. subtilis 168 (Chen et al., 2009).The ORFs encoding Bmy A (3,982 amino acids), Bmy B (5,633 amino acids), and Bmy C (2,619 amino acids) are organized like their respective counterparts in the iturin A and mycosubtilin operons (Fig.4). They show strong sequence similarity with those components and consist of an ordered arrangement of domains involved in condensation, adenylation, and thiolation (Chen et al., 2009). Seven amino acidactivating modules can be distinguished: A1, located in Bmy A; Bmy B1, Bmy B2, Bmy $\mathrm{B} 3$, and Bmy B4, located in Bmy B, and $\mathrm{C} 1$ and $\mathrm{C} 2$, located in Bmy $\mathrm{C}$. The modules B1, $\mathrm{B} 2$, and $\mathrm{C} 1$ also contain epimerization domains, directing conversion of amino acids 2, 3, and 6 in a $\mathrm{D}$-configuration. The last domain of this multienzyme system is a thioesterase domain, which is presumably required for release and circularization of the synthesized lipopeptide molecule (Koumoutsi et al., 2004; Chen et al., 2009).

In $B$. amyloliquefaciens GA1, the itu operon directing the synthesis of iturin $A$ in $B$. subtilis
RB14 (Tsuge et al., 2001) and the bmyL gene cluster in B. subtilis A1/3 (Hofemeister et al., 2004) was surprisingly found inserted at exactly the same position as expected bacillomycin $\mathrm{D}$ gene cluster from $B$. amyloliquefaciens FZB42. This suggested that an inter-species horizontal transfer of genes could have occurred between $B$. subtilis and $B$. amyloliquefaciens (Arguelles-Arias et al., 2009).

The evidence of main antifungal agent of $B$. amyloliquefaciens FZB42, bacillomycin D that is regulated in multiple layers was reported by Koumoutsi et al., (2007). Expression of the bacillomycin D operon (bmy) is dependent on a single $\sigma^{\mathrm{A}}$-dependent promoter, $\mathrm{P}_{\mathrm{bmy}}$ and is favored in its natural host by the small regulatory protein DegQ.

The global regulators DegU and ComA are required for the full transcriptional activation of bmy. DegU retains a key role since it binds directly to two sites located upstream of the bacillomycin D promoter. Moreover, both Deg $\mathrm{U}$ and a transmembrane protein of unknown function, Ycz E, act on a later level of gene expression, exerting their posttranscriptional effects in a hitherto-unknown manner (Koumoutsi et al., 2007).

\section{Detection of bacillomycin}

Stankovic et al., (2012) tested 205 natural isolates of Bacillus spp. for the presence of biosynthetic genes of antimicrobial lipopeptides, iturin, surfactin, fengycin and bacillomycin $\mathrm{D}$. The results of the screening showed that the majority of tested strains had more than one biosynthetic operon, since $81 \%$ possessed the genes for bacillomyin D production, $54 \%$ for surfactin, $38 \%$ for iturin and $25 \%$ for fengycin production, among which the genes for bacillomycin D were highest in the tested strains of Bacillus spp. (Stankovic et al., 2012). 
Mode of action of bacillomycins against plant pathogens

The antagonistic effects of the iturin cyclic peptides are the result of their interaction with the cell membrane and formation of pores (Maget-Dana and Peypoux, 1994). The Tyr residue at position 2 in the peptide ring of peptides from the iturin family has a significant role in the mechanism of pore formation in target cells (Harnois et al., 1989, Volpon et al., 1999). The antimicrobial activity of iturins depends predominantly on its capacity to increase membrane permeabilization, which is being attributed to aggregates formed by iturin molecules, iturinphospholipid complex or iturin-phospholipidsterol complex (Maget-Dana and Peypoux, 1994). The underlying mechanism is based on osmotic perturbation owing to the formation of ion-conducting pores and not membrane disruption or solubilization as caused by surfactins (Aranda et al., 2005).

The detailed study of antimicrobial activity of Bacillus subtilis B-38, isolated from soil against human pathogenic spp. of Candida albicans was done by Tabbene et al., (2011). They revealed the presence of bamC gene producing bacillomycin $\mathrm{D}$ and 3 anti-candida compounds were purified from culture supernatants of the $B$. subtilis which were identified as analogues of bacillomycin D of 14,15 and 16 carbon fatty acid long chains by using MALDI-TOF-MS (Tabbene et al., 2011). These findings suggest that acyl chain length of bacillomycin D like lipopeptides plays a major role in hemolytic and antifungal activities.

Bacillomycin L belonging to the iturin family was originally isolated from the culture broth of B. amyloliquefaciens K103 (Zhang et al., 2013). To understand the actual interaction of iturin family antibiotics with fungal membranes they have studied the antifungal activity of bacillomycin L which involves specific interaction with the intact fungal hyphae of $R$. solani Kühn and investigated in detail by means of various fluorescent techniques, electron microscopy and gel retardation experiment assay. They concluded that the inhibitory activity of bacillomycin L against $R$. solani Kühn not only solely involve membrane permeabilization, but also link to the interaction with the intracellular targets, such as cell 's DNA (Zhang et al., 2013). The antifungal activity of bacillomycin D extracted from $B$. subtilis strain fmbJ against Aspergillus flavus was studied which caused severe injury to both cell wall and cell membrane of fungal spores and hypha (Gong et al., 2014).

Biological control of plant diseases by using Bacillus spp. with AMP (bacillomycins) genes

There has been tremendous research in identification of worthy and notable biocontrol agents, especially Bacillus strains with NRPSs lipopeptide genes which would offer better and more efficient disease control. Ramarathnam et al., (2007) identified for the presence of bamC gene of bacillomycin D synthetase biosynthetic operon in Bacillus cereus DFE4, Bacillus amyloliquefaciens strains DFE16 and BS6, and Bacillus subtilis 49. Both Fengycin and Bacillomycin D were detected in the culture extract of strain BS49, characterized through MALDI-TOF-MS, and their antifungal activities were demonstrated against $F$. graminearum and Sclerotinia sclerotiorum, common fungal pathogens of Canola (Ramarathnam et al., 2007). Likewise, the antagonism of $B$. subtilis strains towards Podosphaera fusca causing cucurbit downy mildew was studied by identifying 3 lipopeptide antibiotics, surfactin, fengycin and iturin A or bacillomycin in butanolic extracts from cell culture filtrates (Romero et al., 2007). 
Fig.1 Primary structures of bacillomycin lipopeptides

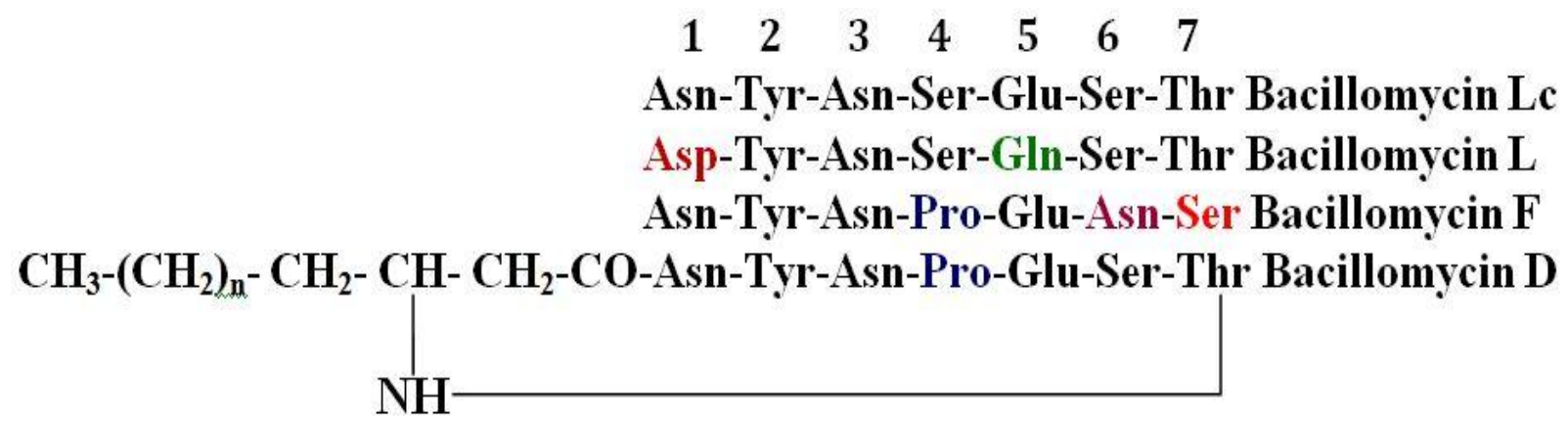

Fig.2 Structure of bacillomycin D (IUPAC name: 3-amino-12-methyl-tri-decanoic acid or 3amino 12-methyl tetradecanoic acid)

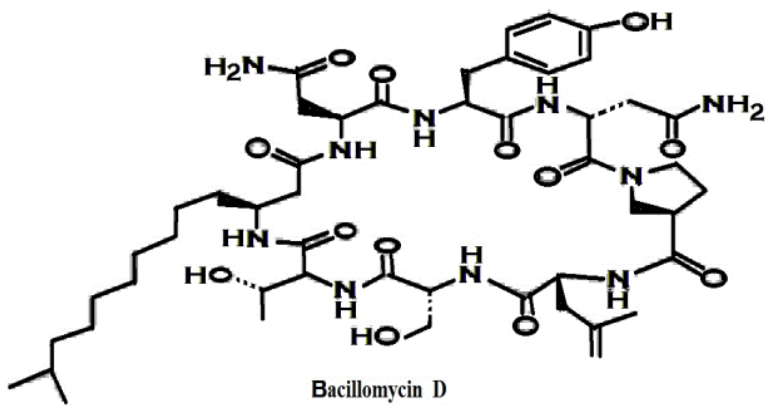

Fig.3 Non-ribosomally synthesized peptide antibiotic bacillomycin D in B. subtilis AU195. In each line, the genetic organization of the NRPSs (boxed) and schematic representations of produced peptide antibiotics and their possible isoforms are given. Amino acid residues, usually in L-configuration, are shown in the single-letter code, and residues in D-configuration are underlined; the fatty acid moieties are hatched and the number of their carbon atoms are indexed (Ci). Each modularly arranged elongation unit contains a domain for adenylation of the amino acid substrate, a peptidyl carrier protein (PCP) and a condensation domain where the formation of a new peptide bond occurs. In the case of amino acids in D-configuration, the NRPSs contain an additional epimerase domain. Numbers correspond either to the size of the gene clusters (in $\mathrm{kb}$ ) or to the derived molecular mass of the NRPSs (in $\mathrm{kDa}$ ). The iturin lipopeptide family share a $\beta$-amino fatty acid as integral constituent, positions 1-3 of the peptide moiety (L-Asx-D-TyrD-Asx) and an additional D-amino acid at position 6 (Stein, 2005)

Bacilomycin 2) (AU195)
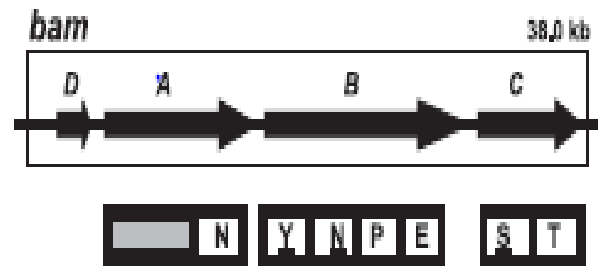

$\mathrm{kDa}$

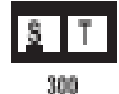

D

F

L

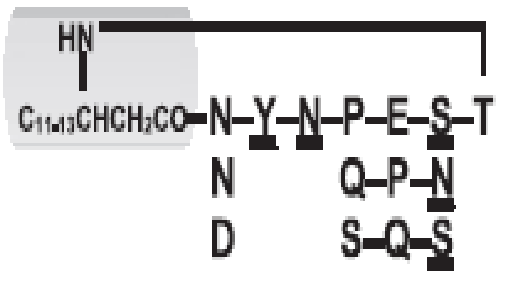


Fig.4 Gene cluster of bacillomycin D (37kb) in FZB42 (Chen et al., 2009)

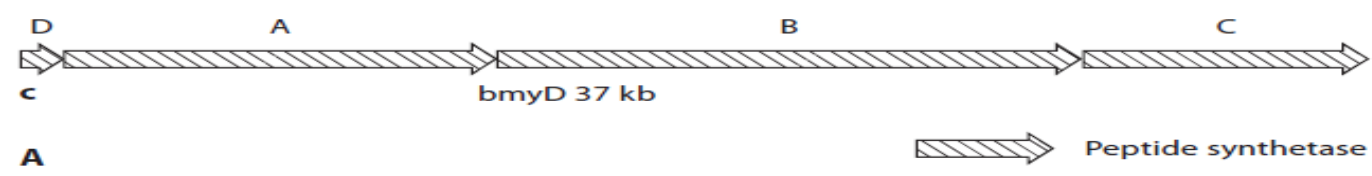

Table.1 Primers for the detection of bacillomycin D biosynthetic genes (Chung et al., 2008)

\begin{tabular}{|c|c|c|c|c|}
\hline Antibiotic & Gene(s) & Primers and sequences & $\begin{array}{l}\text { PCR product } \\
\text { size expected/ } \\
\text { detected }\end{array}$ & $\begin{array}{l}\text { Accession } \\
\text { number/ } \\
\text { Reference }\end{array}$ \\
\hline \multirow[t]{4}{*}{$\begin{array}{l}\text { Bacillomycin } \\
\text { D }\end{array}$} & \multirow[t]{2}{*}{ bam $D$} & $\begin{array}{l}\text { ITUD-F1 } \\
\text { 5'-TTGAAYGTCAGYGC } \\
\text { SCCTTT }\end{array}$ & \multirow[t]{2}{*}{$482 \mathrm{bp} / \mathrm{Yes}$} & $\begin{array}{l}\text { AB050629, } \\
\text { ATTCAU195 }\end{array}$ \\
\hline & & $\begin{array}{l}\text { ITUD-R1 } \\
\text { 5'-TGCGMAAATAATGG } \\
\text { SGTCG }\end{array}$ & & $\begin{array}{l}\text { L42526, } \\
\text { AF499447 }\end{array}$ \\
\hline & \multirow[t]{2}{*}{ bam $C$} & $\begin{array}{l}\text { BAMC-F1 } \\
\text { 5'-AGTAAATGAACGCG } \\
\text { CCAATC }\end{array}$ & \multirow[t]{2}{*}{$957 \mathrm{bp} / \mathrm{No}$} & AY137375 \\
\hline & & $\begin{array}{l}\text { BAMC-R1 } \\
\text { 5'-CCCTCTCCTGCCAC } \\
\text { ATAGAG }\end{array}$ & & AY137375 \\
\hline
\end{tabular}

The purified lipopeptide fractions strongly inhibited the conidia germination of $P$. fusca which were supported by site-directed mutagenesis analysis, targeted to suppress the biosynthesis of different lipopeptides and concluded the major role of iturin and fengycin families in the antagonism of $B$. subtilis towards $P$. fusca (Romero et al., 2007).

The B. subtilis ME 488 isolate suppressed the growth of $F$. $o$. f.sp. cucumerinum and Phytophthora capsici on pepper in pot assays. PCR study confirmed the presence of 11 antibiotics in the Bacillus isolates in which bacillomycin D was also present (Chung et al., 2008). The bacterium B. subtilis $\mathrm{H} 215$ isolated from honey showed high antifungal activity against Byssochlamys fulva $\mathrm{H} 25$, a spoilage mould of juices and beverages (Lee et al., 2008). The purified AMP was found with 5 active fractions which were lyophilized and subjected to mass spectrometry, wherein the five peaks were determined to be identical to bacillomycin $\mathrm{F}$, varying in the length of the fatty acid chain moiety from $\mathrm{C} 14$ to $\mathrm{C} 16$. The AMP was found to be stable over a wide $\mathrm{pH}$ range and upto $100^{\circ} \mathrm{C}$ temperature which was first report of honey microflora producing bacillomycin $\mathrm{F}$ or any antifungal compound (Lee et al., 2008).

Biological activity of Bacillus amyloliquefaciens FZB42 against Fusarium oxysporium was found due to the presence of bacillomycin D mainly (Koumoutsi et al., 2004). The complete genome sequence of this strain FZB42 was given by Chen et al., (2007). The bmy gene cluster was found to be an insertion within the FZB42 genome and separated by only $25 \mathrm{~kb}$ from fengycin gene cluster and they described the synergism of both bacillomycin $\mathrm{D}$ and fengycin by producing double mutants for respected 
lipopeptide gene via gene replacement strategy (Koumoutsi et al., 2004). Similar results were produced in FZB42 strain for its biocontrol activity and respective mutants for all the lipopeptide genes present were assayed in direct growth tests and by bioautography (Chen et al., 2009).

Bacillus amyloliquefaciens FZB42 inhibited growth of plant pathogenic fungi as Fusarium spp. including $F$. oxysporum, Gaeumannomyces graminis, Rhizoctonia solani, Alternaria alternata and Pythium aphanidermatum whilst mutant strains deficient in bacillomycin D production were severely impaired in their antifungal activity suggesting that bacillomycin D contributes significantly to its antifungal activity (Chen et al., 2009).

Interestingly the antagonism of bacillomycins produced by Bacillus isolates against the lipopeptides of pathogens is also being studied. The activity of bacillomycin D (nC14) and bacillomycin D (iso-C15) isolated from $B$. vallismortis ZZ185 against the activity of the lipopeptides of fungal pathogens, $F$. graminearum, A. alternata, $R$. solani, $C$. parasitica and $P$. capsci was elaborated by Zhao et al., (2010).

Moreover, antagonistic endophytic bacterial species are taken for biological control from the hosts in order to control the particular diseases which are having huge antimicrobial activity and plant growth promoting factors rather than the one isolated from the rhizosphere or phyllosphere of the concerned host plants. An endophytic bacterium, $B$. amyloliquefaciens CGMCC 5569 was isolated from medicinal plant Ginkgo biloba showed growth inhibition activity (> 65\%) against sapstain fungi Lasiodiplodia rubropurpurea, $L$. crassispora and $L$. theobromae which is a serious problem of timber, paper and pulp producers based on petriplate study. The antifungal compounds were obtained as a series of lipopeptides, fengycin, surfactin and bacillomycin (Yuan et al., 2012).

The endophytic Bacillus spp. were isolated from seeds of several varieties of maize, Indian popcorn and yellow dent corn varieties which were tested for their antifungal activity against Fusarium moniliforme (Gond et al., 2015). The presence of antifungal lipopeptides genes of iturin A, fengycin and bacillomycin was detected by MALDI-TOFMS. Also they tested the induction of defense gene expression in the host after treating them with B. subtilis (SG-JW-03), wherein the treated roots showed the induction of PRgenes, PR-1 and PR-4 (Gond et al., 2015).

The antimicrobial peptides (AMPs) have wider diversity in their applications commercially, but with the limitation of high production costs in huge quantities.

To reduce this high production costs researchers have utilized low cost raw substrates to produce AMPs or lipopeptides such as rice straw (Zhu et al., 2013), potato (Fox et al., 2000), orange peels (Ghribi et al., 2011) and waste frying oils (Li et al., 2016).

The primary antifungal substances, bacillomycin L, fengycin and surfactin were isolated from cell suspension of Bacillus amyloliquefaciens SYBC H47 isolated from raw honey against Botryosphaeria dothidea under laboratory and field conditions, among which bacillomycin $\mathrm{L}$ showed the best inhibitory effect against conidial germination of $B$. dothidea. In order to raise the lipopeptide yield levels waste frying peanut oil and soy oil as the sole carbon source was utilized and in field trial, the decrease in infected gummosis rate (IGR) and disease severity index (DSI) through cell free suspension treatments of B. amyloliquefaciens SYBC H47 was observed (Li et al., 2016). 
The antagonistic bacteria Bacillus subtilis PSB5 (KJ817861), B. amyloliquefaciens PSB6 (KJ817862) and B. tequilensis PSB8 (KJ817864) were found to be very effective against $F$. $o$. f. sp. gerberae (FOG) (KJ570974) both under in-vitro and protected cultivation conditions with plant growth promoting activities as it was comprising the AMP producing genes as Itu C, Itu D, Bam C, Fen D, Srf A, SfP (Suneeta et. al., 2016a). Similarly the same strains of Bacillus (PSB6 and PSB8) carrying the lipopeptide biosynthetic genes were found to be highly effective under laboratory and field conditions against the polyphagous pathogen Sclerotium rolfsii (first report in Gerbera jamesonii in Tamil Nadu, India) causing collar rot disease in Gerbera (Suneeta et al., 2016b).

A strain of Bacillus subtilis namely Czk1 was isolated from the aerial roots of rubber trees which exhibited the strongest antagonistic activity against Ganoderma pseudoferreum, phellinus noxius, Helicobasidium compactum, Rigidoporus lignosus, Sphaerostilbe repens and Colletotrichum gleosporiodes (He et al., 2017). The crude antibiotic extract was purified, cloned the lipopeptide genes and analysed by MALDI-TOF-MS as surfactin, iturin, fengycin and bacillomycin antibiotics suggesting the strain Czk1 as potential disease biocontrol and is the first report of $B$. subtilis strain from Hevea brasiliensis co-producing these many variants of lipopeptides (He et al., 2017).

The volatile and agar diffusible antifungal metabolites produced by Bacillus velezensis G341 isolated from 4-year old roots of Korean ginseng with strong antifungal activity against various phytopathogenic fungi due to the production of 2 antifungal compounds, bacillomycin $\mathrm{L}$ and fengycin $\mathrm{A}$ and volatile compounds emitted as DMSO, 1butanol and acetoin identified from GC-MS (Lim et al., 2017).

\section{An outlook}

Among the antimicrobial compounds, cyclic lipopeptides (LPs) of the iturin, surfactin and fengycin families have well recognized wider uses in biomedicine and biotechnological applications because of their surfactant, antimicrobial and drug transportation properties. In this review, we have tried to give a picture about bacillomycins in a frame of its entire molecular studies with a great commercialization potential. So far there is few research and patents on individual bacillomycin antibiotic commercial production from its promising Bacillus strains, though its importance is incredible in antifungal activity against plant diseases. Inulin was proved to be the efficient enhancer of bacillomycin D production from B. subtilis strain fmbJ which promoted the bacillomycin D biosynthetase gene (Qian et al., 2015). Also they tested L-glutamine singly and in combination with inulin which significantly raised the bacillomycin $\mathrm{D}$ production to 1.93 g/L (Qian et al., 2017).

Although, there are limitations with the iturin lipopeptides in case of human drug research area, there have been further studies designed to improve the potential and to reduce the side-effects of bacillomycins successfully. Bacillomycins are specially known for their anti-yeast feature (Tabbene et al., 2011) against dangerous human pathogen Candida spp. but with a hemolytic activity as described above. So the toxic effects, drug resistance and hemolysis activity have been tried to reduce by combining two or more synergistic antimycotic drugs like the synergism of polyene drug amphotericin $\mathrm{B}$ and bacillomycin $\mathrm{D}$ have been described by Tabbene et al., (2015) against Candida spp.

Moreover, there is tremendous research on Bacillus strains producing lipopeptides, their comparative, evolutionary and functional 
genomics, site-directed mutagenesis and strain construction studies including marker removal was successfully done like in $B$. amyloliquefaciens FZB42 (Wu et. al., 2015) which is almost done as a geneticallyengineered (GE) strain against broader range of plant pathogenic fungi. But, reasonable lacunae are present in understanding many molecular mechanisms of the BCAs in plant spheres to further pave a way in achieving commercialization of a lipopeptide antibiotic or a GE strain of BCAs successfully.

\section{References}

Aranda, F. J., Teruel, A. J., Ortiz, A. 2005. Further aspects on the hemolytic activity of the antibiotic lipopeptide iturin A. Biochim. Biophys. Acta; 1713: 51-56.

Arguelles-Arias, A., Ongena, M., Halimi, B., Lara, Y., Brans, A., Joris, B., Fickers, P. 2009. Bacillus amyloliquefaciens GA1 as a source of potent antibiotics and other secondary metabolites for biocontrol of plant pathogens. Microbial Cell Factories; 8: 63.

Besson, F. and Michel, G. 1992. Biosynthesis of bacillomycin $\mathrm{D}$ by Bacillus subtilis Evidence for amino acid-activating enzymes by the use of affinity chromatography. FEBS letters; 308 (1): 18-21.

Besson, F., Michel, G. 1986. Isolation and characterization of new iturins: iturin $\mathrm{D}$ and iturin E. The Journal of Antibiotics; XI: 437-442.

Besson, F., Peypoux, F., Michel, G., Delcambe, L. 1976. Characterization of iturin A in antibiotics various strains of Bacillus subtilis. The Journal of Antibiotics; 10: 1043-1049.

Besson, F., Peypoux, F., Michel, G., Delcambe, L. 1978. Identification of antibiotics of iturin group in various strains of Bacillus subtilis. The Journal of Antibiotics: 31(4): 284-288.

Besson, F., Peypoux, G., Michel, G., Delcambe, L. 1977. Structure de la bacillomycine L, antibiotique de Bacillus subtilis. European Journal of Biochemistry; 77: 61-67.

Chen, H. X., Koumoutsi, A., Scholz, R., Borris, R. 2009. More than Anticipated Production of Antibiotics and Other Secondary Metabolites by Bacillus amyloliquefaciens FZB42. Mol Microbiol Biotechnol; 16: 14-24.

Chen, X. H., Koumoutsi, A., Scholz, R., Eisenreich, A., Schneider, K., Heinemeyer, I., Morgenstern, B., Voss, B., Hess, W. R., Reva, O., Junge, H., Voigt, B., Jungblut, P. R., Vater, J., Süssmuth, R., Liesegang, H., Strittmatter, A., Gottschalk, G., Borriss, R. 2007. Comparative analysis of the complete genome sequence of the plant growthpromoting bacterium Bacillus amyloliquefaciens FZB42. Nat Biotechnol; 25:1007-1014.

Cho, S. J., Lee, S. K., Cha, B. J., Kim, Y. H., Shin, K. S. 2000. Detection and characterization of the Gloeosporium gloeosporioides growth inhibitory compound iturin A from Bacillus subtilis strain KS03. FEMS Microbiology; 223: 47-51.

Chung, S., Kong, H., Buyer, S. J., Lakshman, K. D., Lydon, J., Kim, S. D., Roberts, P. D. 2008. Isolation and partial characterization of Bacillus subtilis ME488 for suppression of soilborne pathogens of cucumber and pepper. Appl Microbiol Biotechnol; 80: 115-123.

Duitman, E. H., Hamoen, L. W., Rembold, M., Venema, G., Seitz, H., Saenger, W., Bernhard, F., Reinhardt, R., Schimdt, M., Ullrich, C., Stein, T., Leenders, F., Vater, J. 1999. The mycosubtilin synthetase of Bacillus subtilis ATCC6633: A multifunctional hybrid between a peptide synthetase, an amino transferase and a fatty acid synthase. PNAS; 96 (23): 13294-13299.

Eshita, M. S. and Roberto, N. H. 1995. Bacillomycin Lc, a New Antibiotic of the Iturin Group: Isolations, Structures, and Antifungal Activities of the Congeners. 
The journal of antibiotics; 48 (11): 12401247.

Finking, R., and Marahiel, M.A. 2004. Biosynthesis of non-ribosomal peptides. Annu Rev Microbiol; 58: 453-488.

Fox, S. L., Bala, G. A.2000. Production of surfactant from Bacillus subtilis ATCC 21332 using potato substrates. Bioresource technology; 75(3):235-240.

Ghribi, D., Mnif, I., Boukedi, H., Kammoun, R., Ellouze-Chaabouni, S. 2011. Statistical optimization of low-cost medium for economical production of Bacillus subtilis biosurfactant, a biocontrol agent for the olive moth Prays oleae. African Journal of Microbiology Research; 5(27):4927-4936.

Gond, K. S., Bergen, S. M., Torres, M. S., White Jr., J. F. 2015. Endophytic Bacillus spp. produce antifungal lipopeptides and induce host defence gene expression in maize. Microbiological Research; 172: 79-87.

Gong, Q., Zhang, C., Lu, F. 2014. Identification of bacillomycin D from Bacillus subtilis fmbJ and its inhibition effects against Aspergillus flavus. Food Control; 36(1):8-14.

Guenzi, E., Galli, G., Grgurina, I., Paces, E., Ferranti, P., Grandi, G. 1998. Coordinate transcription and physical linkage of domains in surfactin synthetase are not essential for proper assembly and activity of the multienzyme complex. $J$ Biol Chem; 273: 14403-14410.

Harnois, I., Maget-Dana, R., Ptak, M.1989. Methylation of the antifungal lipopeptide iturin A modifies its interaction with lipids. Biochimie. 71: 111-116.

He, C. P., Fan, L. Y., Wu, W. H., Liang, Y. Q., Li, R., Tang, W., Zheng, X. L., Xiao, N. Y., Liu, Z. X., Zheng, F. C. 2017. Identification of lipopeptides produced by Bacillus subtilis Czk1 isolated from the aerial roots of rubber trees. Genet. Mol. Res; 16 (1): 1-13.

Hofemeister, J., Conrad, B., Adler, B., Hofemeister, B., Feesche, J., Kucheryava, N., Steinborn, G., Franke, P., Grammel,
N., Zwintscher, A., Leenders, F., Hitzeroth, G., Vater., J. 2004. Genetic analysis of the biosynthesis of nonribosomal peptide- and polyketide-like antibiotics, iron uptake and biofilm formation by Bacillus subtilis A1/3. Mol. Genet. Genomics; 272: 363-378.

Kohli, R.M., and Walsh, C.T. 2003. Enzymology and acyl chain macrocyclization in natural product biosynthesis. Chem Commun (Camb); 7: 297-307.

Koumoutsi, A., Chen, X. H., Vater, J., Borriss, R. 2007. DegU and YczE positively regulate the synthesis of bacillomycin $\mathrm{D}$ by Bacillus amyloliquefaciens strain FZB42. Appl Environ Microbiol; 73: 6953-6964.

Koumoutsi, A., X. H. Chen, A. Henne, H. Liesegang, G. Hitzeroth, P. Franke, J. Vater, and R. Borriss. 2004. Structural and functional characterization of gene clusters directing nonribosomal synthesis of bioactive cyclic lipopeptides in Bacillus amyloliquefaciens strain FZB42. J. Bacteriol; 186:1084-1096.

Lambalot, R. H., Gehring, A. M., Flugel, R. S., Zuber, P., La Celle, M., Marahiel, M. A. 1996. A new enzyme superfamily - the phosphopantetheinyl transferases. Chem Biol; 3: 923-936.

Lee, H., Churey, J. J., Worobo, R. W. 2008. Purification and structural characterization of bacillomycin $\mathrm{F}$ produced by a bacterial honey isolate active against Byssochlamys fulva $\mathrm{H} 25$. Journal of Applied Microbiology; 105: 663-673.

Li, X., Zhang, Y., Wei, Z., Guan, Z., Cai, Y., Liao, X. 2016. Antifungal Activity of Isolated Bacillus amyloliquefaciens SYBC H47 for the Biocontrol of Peach Gummosis. PLoS ONE; 11(9): 1-22.

Lim, S. M., Yoon, M. Y., Choi, G. Y., Choi, Y. H., Jang, K. H., Shin, T. S., Park, H. W., Yu, N. H., Kim, Y. H., Kim, J. C. 2017. Diffusible and Volatile Antifungal Compounds Produced by an Antagonistic Bacillus velezensis G341 against Various 
Phytopathogenic Fungi. Plant Pathol. J.; 33(5): 488-498.

Maget-Dana, R., Peypoux, F.1994. Iturins, a special class of pore-forming lipopeptides: biological and physicochemical properties, Toxicology; 87: 151-174.

Moyne, A. L., Cleveland, T. E., Tuzun, S. 2004. Molecular characterization and analysis of the operon encoding the antifungal lipopeptide bacillomycin D. FEMS Microbiol Lett, 234: 43-49.

Ongena, M. and Jacques, P.2007. Bacillus lipopeptides: versatile weapons for plant disease biocontrol. Trends in microbiol.; 16 (3): 115-125.

Peypoux, F., Besson, F., Michel, G., Delcambe, L. 1979. Preparation and antibacterial activity upon Micrococcus luteus of derivatives of iturin $\mathrm{A}$, mycosubtilin and bacillomycin L, antibiotic from Bacillus subtilis. Biochemical Biophysical Research Communications; 2(2): 136140.

Peypoux, F., Besson, F., Michel, G., Delcambe, L. 1981. Structure of Bacillomycin D, a New Antibiotic of the Iturin Group. Eur J Biochem; 118: 323-327.

Peypoux, F., Guinand, M., Michel, G., Delcambe, L., Das, B. C., Lederer, E. 1978. Structure of iturin A, a peptidolipid antibiotic from Bacillus subtilis. Biochemistry; 17: 3992-3996.

Peypoux, F., Guinand, M., Michel, G., Delcambe, L., Das, B. C., Varenne, P., Lederer, E. 1973. Isolement de l'acide 3amino 12-methyl tetradecanoique et de l'acide 3-amino 12-methyl teridecanoique a partir de l'iturine, antibiotique de Bacillus subtilis. Tetrahedron; 29: 34553459.

Peypoux, F., Marion, D., Maget-Dana, R., Ptak, M., Das, B. C., Michel, G. 1985. Structure of bacillomycin F, a new peptidolipid antibiotic of the iturin group. Eur. J. Biochem. 153: 335-340.

Peypoux, F., Pommier, M. T., Das, B. C., Besson, F., Delcambe, L., Michel, G. 1984. Structures of bacillomycin D and bacillomycin $\mathrm{L}$ peptidolipid antibiotics from Bacillus subtilis. The Journal of Antibiotics; 77: 1600-1604.

Qian, S., Lu, H., Meng, P., Zhang, C., Li, X., Bie, X., Lu, Z. 2015. Effect of inulin on efficient production and regulatory biosynthesis of bacillomycin D in Bacillus subtilis fmb. J. Bioresource Technology; 179: 260-267.

Qian, S., Sun, J., Lu, H., Lu, F., Bie, X., Lu, Z. 2017. L-Glutamine efficiently stimulates biosynthesis of bacillomycin D in Bacillus subtilis fmb. J. Process biochemistry; 58: 224-229.

Ramarathnam, R., Bo, S., Chen, Y., Fernando, W. G. D., Xuewen, G., De Kievit, T. 2007. Molecular and biochemical detection of Fengycin and Bacillomycin D producing Bacillus spp. antagonistic to fungal pathogens of canola and wheat. Can. J. Microbiol; 53: 901-911.

Romero, D., De Vicente, A., Rakotoaly, R. H.2007. The iturin and fengycin families of lipopeptides are key factors in antagonism of Bacillus subtilis toward Podosphaera fusca. Mol Plant-Microbe Interact; 20(4):430-440.

Stankovic, S., Mihajlovic, S., Draganic, V., Dimkic, I., Vukotic, G., Beric, T., Fira, D. 2012. Screening for the presence of biosynthetic genes for antimicrobial lipopeptides in natural isolates of Bacillus sp. Arch. Biol. Sci.; 64 (4): 1425-1432.

Stein, T. 2005. Bacillus subtilis antibiotics: structures, syntheses and specific functions; Molecular Microbiology; 56 (4): 845-857.

Stein, T., Vater, J., Kruft, V., Otto, A., Wittmann-Liebold, B., Franke, P. 1996. The multiple carrier model of nonribosomal peptide biosynthesis at modular multienzymatic templates. J Biol Chem; 271: 15428-15435.

Suneeta, P., Eraivan, A. A. K., Nakkeeran, S. 2016a. Investigations on Antifungal Activity of Bacillus spp. against Fusarium oxysporum f. sp. gerberae (FOG) Causing Wilt of Gerbera Under Protected Cultivation. J.of pure and 
applied microbiology; 10 (3): 2099-2111.

Suneeta, P., Eraivan, A. A. K., Nakkeeran, S. 2016b. Efficacy of Bacillus spp. in the management of collar rot of Gerbera under protected cultivation. Res. on Crops; 17 (4): 745-752.

Tabbene, O., Antonio, D. G., Sana, A., Imen, B. S., Salem, E., Najib, A. M., Bruno, C., Vincenzo, L., Ferid, L., Liusa, M. M. 2015. Synergistic fungicidal activity of the lipopeptide bacillomycin D with amphotericin B against pathogenic Candida species. FEMS Yeast Research; 15 (4): 1-7.

Tabbene, O., Kalai, L., Ben Slimen, I. 2011. Anti-Candida effect of bacillomycinDlike lipopeptides from Bacillus subtilis B38. FEMS Microbiol Lett; 316: 108114.

Tsuge, K., Ano, T. and Shoda, M. 1996. Isolation of a gene essential for biosynthesis of the lipopeptide antibiotics plipastatin B1 and surfactin in Bacillus subtilis YB8. Arch. Microbiol; 165: 243251.

Volpon, L., Besson, F., Lancelin, J. M. 1999. NMR structure of active and inactive forms of the sterol-dependent antifungal antibiotic bacillomycin L, Eur. $J$. Biochem. 264: 200-210.

Wu, L., Wu, H. J., Qiao, J., Gao, X., Borriss, R. 2015. Novel Routes for Improving Biocontrol Activity of Bacillus Based
Bioinoculants. Front. Microbiol; 6:1395.

Yu, G. Y., Sinclair, J. B., Hartman, G. L., Bertagnolli, B. L. 2002. Production of iturin A by Bacillus amyloliquefaciens suppressing Rhizoctonia solani. Soil Biology and Biochemistry; 34: 955-963.

Yuan, B., Wang, Z., Qin, S., Zhao, G. H., Feng, Y. J., Wei, L. H., Jiang, J. H. 2012. Study of the anti-sapstain fungus activity of Bacillus amyloliquefaciens CGMCC 5569 associated with Ginkgo biloba and identification of its active components. Bioresource Technology; 114: 536-541.

Zhang, B., Dong, C., Shang, Q., Han, Y., Li, P. 2013. New insights into membrane-active action in plasm membrane of fungal hyphae by the lipopeptide antibiotic bacillomycin L. Biochimica et Biophysica Acta; 1828: 2230-2237.

Zhao, Z., Wang, Q., Wang, K. 2010. Study of the antifungal activity of Bacillus vallismortis ZZ185 in vitro and identification of its antifungal components. Bioresour Technol; 101(1): 292-297.

Zhu, Z., Zhang, F. G., Wei, Z., Ran, W., Shen, Q. R. 2013. The usage of rice straw as a major substrate for the production of surfactin by Bacillus amyloliquefaciens XZ-173 in solid-state fermentation. Journal of Environmental Management; 127:96-102.

\section{How to cite this article:}

Suneeta, P., K. Eraivan Arutkani Aiyanathan and Nakkeeran, S. 2018. Bacillomycins - The Effective Molecules in Plant Disease Management. Int.J.Curr.Microbiol.App.Sci. 7(02): 823835. doi: https://doi.org/10.20546/ijcmas.2018.702.104 